\title{
Bronchial carcinoma and hypercalcaemia
}

\author{
J. G. AZZOPARDI AND R. S. WHITTAKER
}

From the Department of Morbid Anatomy, Royal Postgraduate Medical School of London, London

SYNOPSIS Hypercalcaemia due to malignant disease, in the absence of bone metastases, is generally $\overrightarrow{\vec{\omega}}$ regarded as a rare event. It occurred in $16 \%$ of a series of cases of bronchial carcinoma coming to necropsy. Hypercalcaemia is a relatively common complication of bronchial carcinoma.

The hypercalcaemia is usually accompanied by hypophosphataemia and, in this respect, must be $\mathrm{N}_{N}$ distinguished from the hypercalcaemia that may be found with breast carcinoma. It is frequently accompanied by hypokalaemic alkalosis; this must not be confused with the metabolic disorder $\vec{\infty}$ that results from the production of ectopic 'ACTH'.

The bones sometimes show changes of osteitis fibrosa akin to those seen in hyperparathyroidism. Cystic disease of bone recognizable radiologically is rare, probably because of the relatively short $z$ duration of the metabolic disturbance.

The parathyroids are usually mildly atrophic. There is no evidence that the main pathogenetic $\stackrel{\oplus}{3}$ mechanism is stimulation of the parathyroids by the tumour. Acceptable instances of parathyroid $\stackrel{\mathbb{L}}{工}$ hyperplasia are very rare: the significance of these exceptional cases awaits further study.

Squamous carcinoma of the bronchus is the type mainly incriminated. Oat-cell carcinoma and bronchial adenocarcinoma are involved less frequently than expected by chance. The significance of the tumour types implicated is discussed in relation to the possible pathogenesis.

The concept of hypercalcaemia due to malignant disease, in the absence of bone metastases, was established by Plimpton and Gellhorn in 1956. Other reports have confirmed this, but the impression remains that this is a relatively rare event, though some gratifying results have been obtained by resection in severely ill patients. Lipsett, Odell, Rosenberg, and Waldmann (1964) found only 26 well documented cases in the literature. Our experience with a necropsy series of bronchial carcinomas is reported.

MATERIAL AND METHODS

All cases of bronchial carcinoma coming to necropsy between September 1966 and December 1967 are included. These number 51 tumours in 50 patients (one patient had two distinct tumours). They include 29 patients without and 21 with bone metastases. Eight patients without bone secondaries had hypercalcaemia. The presence of osseous metastases does not, of course, exclude the additional role of humoral factors in the production of hypercalcaemia; it has even been suggested that such a humoral effect may itself increase the incidence of osseous metastases (Pentimalli, 1960).

The clinical, radiographic, and biochemical data of these eight cases were analysed and correlated with

Received for publication 5 March 1969. necropsy findings. In particular other possible causes of hypercalcaemia were rigorously excluded; radiological $\stackrel{2}{\overrightarrow{2}}$ bone study helped to localize possible bone metastases, 응 and extensive biochemical investigations confirmed abnormalities and helped to follow the effects of treatment. Tumour distribution at necropsy was carefully charted. Vertebral strips, including all dorsal and lumbar $\bar{\imath}$ vertebrae, the sternum, one rib, the right femur, and a? segment of the left iliac crest, were examined. In several cases bone examination was more extensive; where clinical or radiological data suggested even remotely the $\delta$ possibility of bone deposits, the relevant bones were examined. Numerous bones were sectioned for evidence $ᄋ$ of hyperparathyroid-like changes.

RESULTS

The main clinico-pathological data are summarized $N$ in Table 1. There are six men and two women with $\omega$ an age range of 58 to 76 years. Five of the tumours are squamous, two are adenocarcinomas, and one is a large-cell carcinoma that could not be identified $\mathbb{\Phi}$ further. Of the squamous tumours one is fairly well ${ }^{+}$ differentiated, one shows moderate differentiation, $\frac{T}{0}$ while in three the tumours are poorly differentiated $\underset{\mathbb{D}}{\stackrel{O}{ }}$ with considerable pleomorphism and areas of tumour $\stackrel{\square}{\square}$ giant cells (Figs. 1 and 2). Of the adenocarcinomas, $\stackrel{\unrhd}{\unrhd}$ one is very poorly differentiated with pleomorphic 


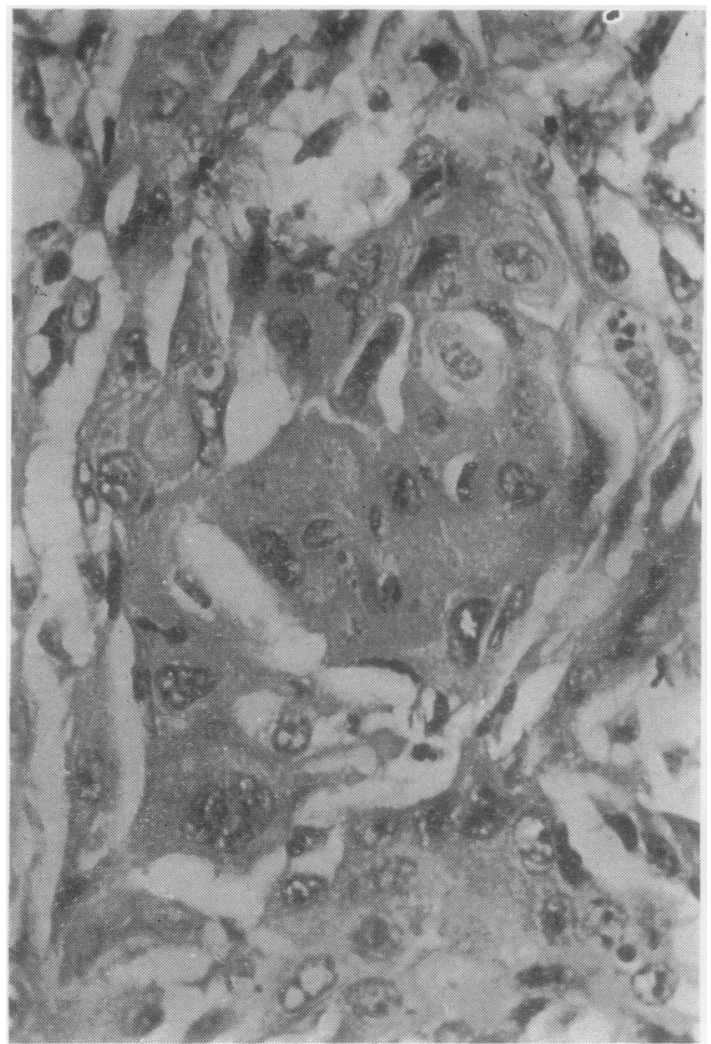

FIG. 1. Focus of squamous differentiation in an otherwise largely undifferentiated squamous carcinoma. Haemalum and eosin $\times 400$.

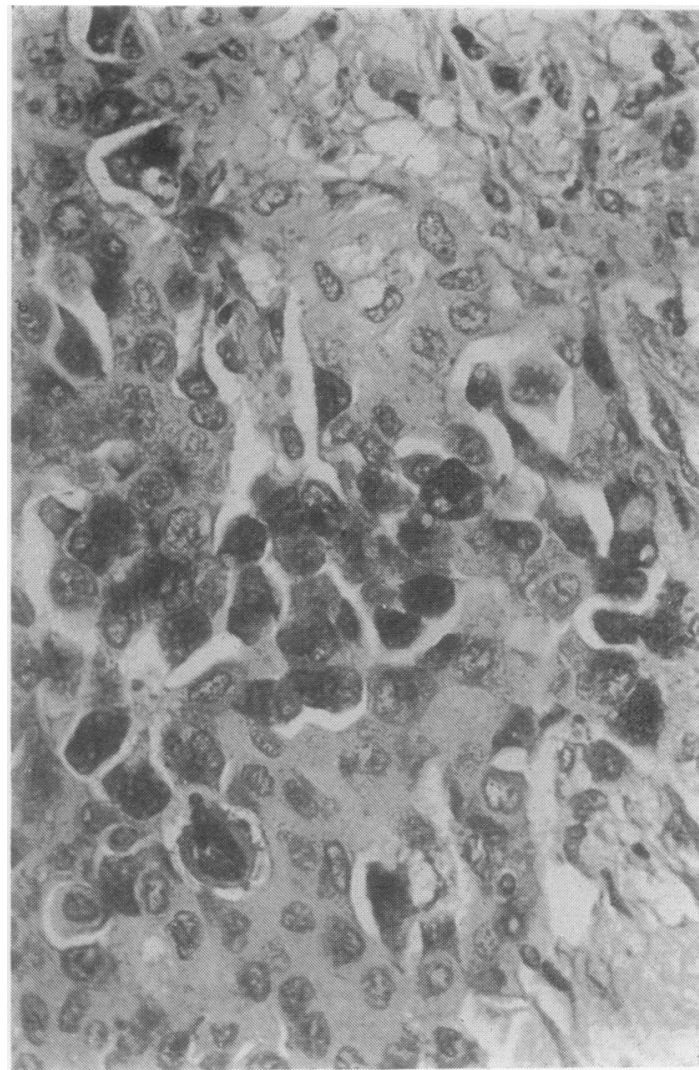

FIG. 3. Adenocarcinoma with intracellular mucin se-ํㅗำ cretion. The secretory cells appear dark in the photomicrograph. Diastase-periodic-acid-Schiff $\times 400$.

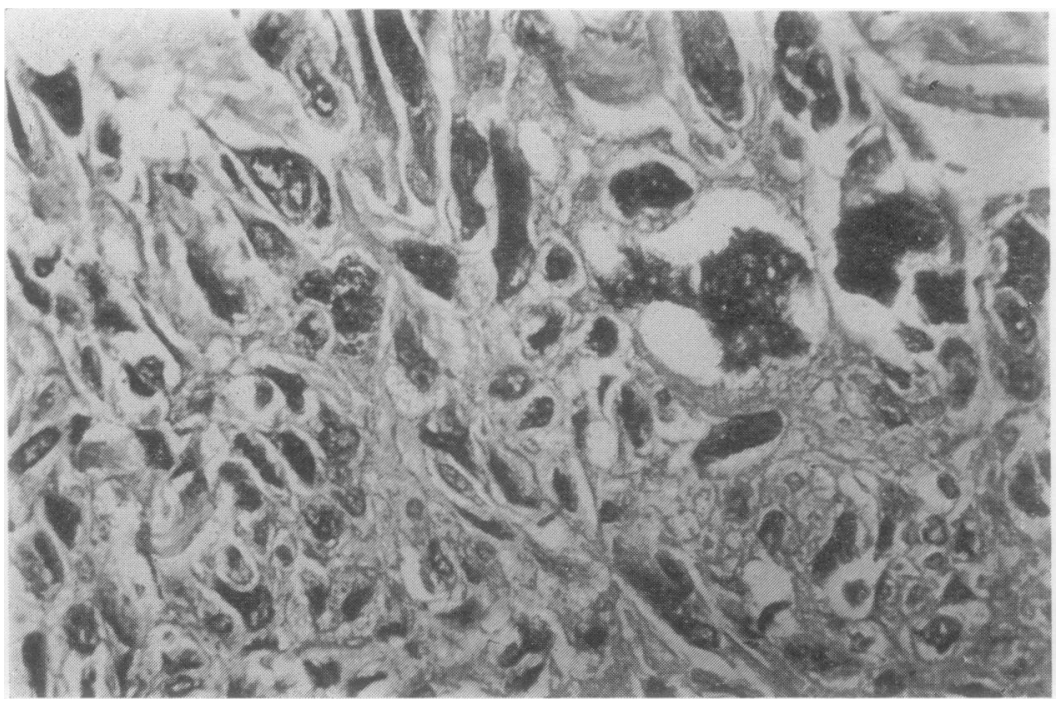

FIG. 2. Pleomorphic squamous carcinoma with tumour giant $\mathcal{O}^{-}$ cells. Haematoxylin and eosin $\times 400$. 
sequently lost. All four parathyroids were found, weighed and studied microscopically in three cases. Total parathyroid weight was $100.8 \mathrm{mg}, 100.0 \mathrm{mg}$, and $132 \mathrm{mg}$ respectively. This represents an average weight of $111 \mathrm{mg}$ for two male and one female patient. In the eighth case only two small parathyroids were identified.Microscopically, the amount of adipose tissue in the parathyroids varied greatly in different patients, and slightly between different glands in the same patient; the overall estimate for adipose tissue was between 5 and $30 \%$ of the parathyroid gland. If fibrous stroma, onkocytic foci, or other inactive tissue, eg, microcysts, are added, a figure between 10 and $40 \%$ for different cases is obtained. The amount of adipose tissue is small for patients of this age. Reduction in adipose tissue has been responsible for similar parathyroids being labelled 'hyperplastic' in the literature: the validity of this belief is discussed later. The relationship between small size of the chief cells of the parathyroid and increased functional activity is still

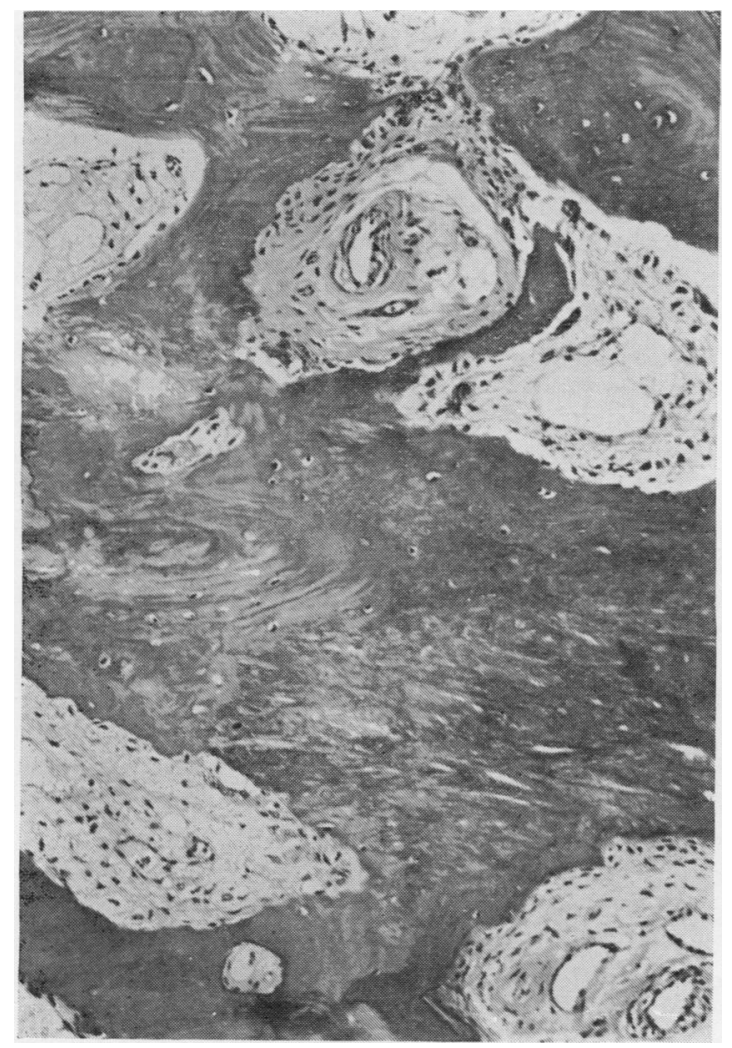

FIG. 4. debatable. Low glycogen content and argyrophilia of secretion granules are useful criteria (Roth, 1964), but we found them inapplicable to necropsy material.

Bone metastases were absent, since selection was on this basis. In one patient, though a solitary scapular metastasis detected radiologically was confirmed at necropsy, there was no evidence of this at the time hypercalcaemia was detected and, more pertinently, pneumonectomy corrected the biochemical abnormalities, the serum calcium level subsequently remaining normal for nine weeks. It rose again concomitantly with the detection of the scapular tumour. While this terminal hypercalcaemia may have been due in part at least to bone destruction, the initial hypercalcaemia was not. This case was therefore retained in the series.

Bone changes like those of hyperparathyroidism were present in three of the eight cases (Figs. 4, 5, and 6). There was evidence of resorption with increased osteoclasts, Howship's lacunae, jagged bony trabeculae, wisps or larger areas of loose

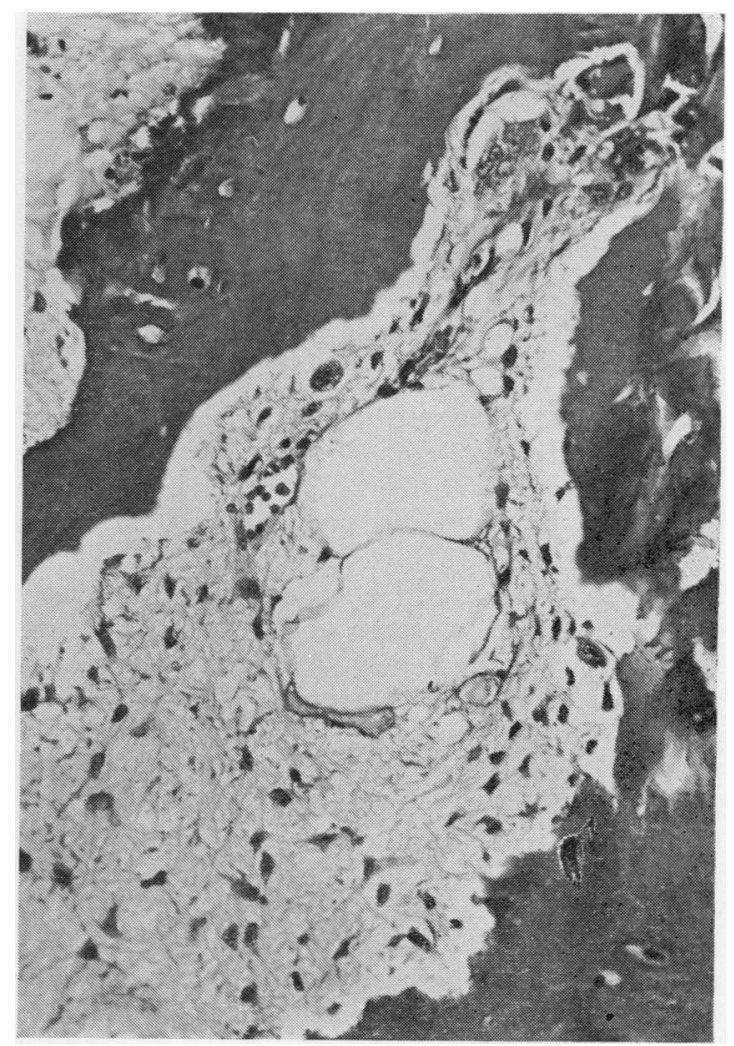

FIG. 5 .

FIG. 4. Osteitis fibrosa in proximal phalanx of a finger. Haematoxylin and eosin $\times 100$.

FIG. 5. Changes of osteitis fibrosa in subperiosteal region of metacarpal bone. A cluster of osteoclasts is visible in the upper right corner. Haematoxylin and eosin $\times 230$. 


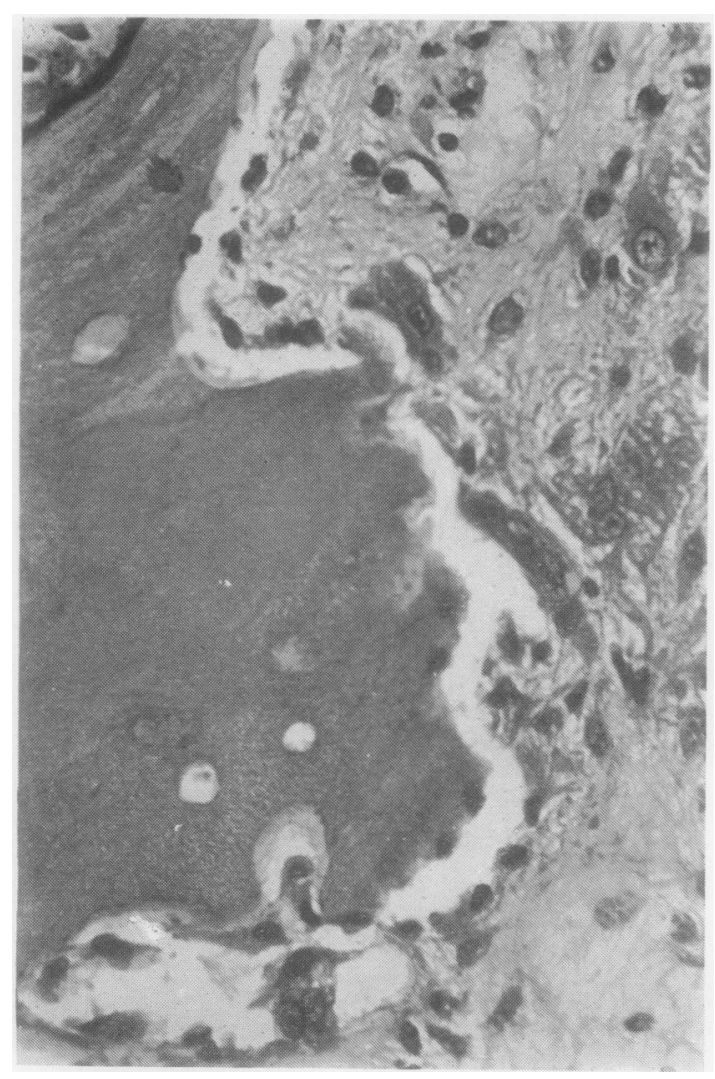

FIG. 6. Osteoclastic resorption in phalanx. Haematoxylin and eosin $\times 400$.

fibrous tissue adjacent to bone trabeculae, and increased osteoblastic activity with increased bone surface covered by osteoid. These three cases with bone changes are the three with a raised serum alkaline phosphatase level, in the absence of hepatic metastases. However, the case with the most prominent bone changes and the most severe hypercalcaemia had only a borderline rise in alkaline phosphatase. Attempts to correlate bone change with duration of hypercalcaemia were not possible, since duration of the hypercalcaemia before its discovery could not usually be inferred. Of the other five patients, one showed mild changes in a few bones only, and in four there were no bone changes of hyperparathyroidism.

One patient had hypertrophic osteoarthropathy, another digital clubbing only. No other metabolic disorders were noted. The hypokalaemic alkalosis is related to the hypercalcaemic disorder and must not be attributed to the production of ectopic 'ACTH' that occurs with oat-cell carcinoma but not with squamous bronchial carcinoma (Azzopardi and Williams, 1968).
The effect of therapy was best seen in case $4, \div$ where the biochemical abnormalities became normal $\vec{F}$ after pneumonectomy, with the exception of the alkaline phosphatase level which was marginally등 elevated during the six weeks postoperatively in $\overline{\frac{\sigma}{5}}$ which it was estimated. In case 7, while having radiotherapy, the patient suddenly complained of marked weakness, severe thirst, and anorexia: this development led to the discovery of hypercalcaemia. $\vec{\circ}$

\section{DISCUSSION}

The incidence of hypercalcaemia in patients with bronchial carcinoma without bone metastases can be 9 calculated from the data given by Locks (1962) as $-\underset{\infty}{ }$ $7.5 \%$. Carey (1966) found a $6 \%$ incidence of symptomatic hypercalcaemia in 100 male patients. ${ }^{.}$ Inorganic phosphate was not estimated. Tumour $\vec{Z}$ types were not given. In our series, $16 \%$ of patientso with bronchial carcinoma coming to necropsy had $\stackrel{\Phi}{\rightrightarrows}$ hypercalcaemia, in the absence of evidence of boneo metastases. If the two cases with slight but definite $\frac{\text { C }}{-}$ hypercalcaemia are excluded, the figure is still $12 \% \cdot \overrightarrow{0}$ While there was no evidence of case selection aftero death, permission for necropsy being sought in allo cases, it is impossible to exclude clinical factors? operating that might tend to keep hypercalcaemic patients in hospital; selection could have exercisedڤ an influence at this stage. Since cases with hyper-市 calcaemia in the presence of bone metastases are disgregarded, the 21 patients with bone metastases could be omitted from the whole series; this would give a figure of $17 \%$ even ignoring the two cases with minimal hypercalcaemia. There are obvious flaws to such a correction; on present evidence it is? probable that between 10 and $15 \%$ of patients witho bronchial carcinoma followed to death have hypercalcaemia (not attributable to bone metastases) atô some stage.

The hypercalcaemia is generally accompanied by윽 hypophosphataemia; this agrees with some pub- $>$ lished data, though statements to the contrary have been made (Leaf, 1961). A sharp distinction must N be made between the hypercalcaemic/hypophos- phataemic syndrome of bronchial carcinoma, renal $N$ carcinoma, and other tumours, and the hypercalcaemia of breast carcinoma which is accompanied by normal or slightly elevated serum phosphateo

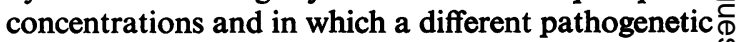
mechanism is thought to operate (Gordan, Cantino, ? Erhardt, Hansen, and Lubich, 1966). The former 0 only is our concern here. Hypokalaemic alkalosis is a frequent finding. Gault and Kinsella (1965) $\stackrel{\mathbb{Q}}{\stackrel{Q}{\odot}}$ believed that metabolic acidosis was the usual $\stackrel{\mathbb{Q}}{\varrho}$ accompaniment but, in view of our findings, we must 
reject this view. The frequency of hypokalaemic alkalosis raises the possibility that the effect of any humoral substance produced by these tumours differs from that of parathormone and may indicate some chemical difference in the parathormone-like substance identified in many of them (Case Records, Massachusetts General Hospital, 1963; Goldberg, Tashjian, Order, and Dammin, 1964; Tashjian, Levine, and Munson, 1964).

The bones have usually been described as normal or showing osteoporosis only. Goldberg et al (1964) showed a raised metabolic rate of bone in vitro. Lamberg, Pelkonen, and Frick (1964) described subperiosteal bone resorption but unfortunately only two parathyroids were identified. In the Case Records, Massachusetts General Hospital (1963) similar radiological changes were described in the radial heads but the latter were not examined pathologically. In our material three of eight cases showed bone changes of osteitis fibrosa, consistent with the concept of the tumour producing a parathormone-like substance.

Another disputed point is the state of the parathyroids. In many cases information is lacking, in others the parathyroids are merely described as 'normal'. In a very few they are called atrophic and in six cases they were regarded as hyperplastic (Grimes, Fisher, Finn, and Danowski, 1967). The problem is fraught with difficulties. Only rarely have four parathyroids been identified, weights are seldom given, and, if criteria for recognizing mild hyperplasia are ill defined, those for recognizing hypoplasia are even more so. Four parathyroids were identified in four of our cases and accurate weights obtained in three. The average weight was less than the normal average (Gilmour and Martin, 1937) and in no case was it above. In the remaining five cases the parathyroids found were not increased in size. Hypoplasia or normal parathyroids, rather than hyperplasia, is therefore the characteristic finding. In two necropsies on patients with non-bronchial carcinomas and the hypercalcaemic syndrome (squamous carcinomas of oesophagus and cervix) in which four and five parathyroids respectively were identified, weighed, and confirmed microscopically, the parathyroids were again hypoplastic (unpublished data), reinforcing our findings with the bronchial carcinomas. The six cases with parathyroid hyperplasia cited by Grimes et al are not convincing, with the exception of the cervical carcinoma described by Stone, Waterhouse, and Terry (1961) and probably the bronchial carcinoma of Massaro and Owen (1962). In Stone's case, despite the partial effectiveness of steroids in reducing hypercalcaemia, primary chief-cell hyperplasia cannot be ruled out. In the case of Keller,
Goldschneider, and Lafferty (1965), the authors did not regard the parathyroids as hyperplastic. In the other three cases cited, four parathyroids were not found or the number found was not stated and, more cogently, the diagnosis of hyperplasia depended on a reduction of adipose tissue, a criterion sometimes useful in the recognition of hyperplasia in a patient operated on for hypercalcaemia thought to be due to hyperparathyroidism. This criterion is probably invalid in the diagnosis of hyperplasia at necropsy in a wasted patient with malignant disease. The relationship between the genuine but very rare case of parathyroid hyperplasia with hypercalcaemia and accompanying malignant disease is obscure.

Hypercalcaemia in bronchial carcinoma has practical implications. The gastrointestinal, cerebral, and general symptoms may be mistaken for those of metastatic disease. The tumour may be resectable with dramatic reversal of the symptoms. Even where metastatic disease is present or with an inoperable tumour, gratifying results can be obtained by biochemical means in relieving distressing symptoms of hypercalcaemia. Many patients die of malignant disease with necropsy findings which are inadequate to explain the symptoms or the patient's death. Recognition of the metabolic effects of tumours has begun to clarify this situation. While Cushing's disease due to 'non-endocrine' malignancy is more widely recognized, the hypercalcaemic syndrome is of greater practical importance because of its relatively common occurrence with common tumours, the ease with which it may be missed clinically, the rapidity with which acute intoxication may result, and its potential reversibility by therapy.

It is important to know whether certain tumours are especially prone to cause hypercalcaemia. 'Non-endocrine' tumours generally have been incriminated in the production of Cushing's syndrome, the Schwartz-Bartter syndrome, the hypercalcaemic syndrome, etc. However, it has been shown (Azzopardi and Williams, 1968) that in the case of Cushing's syndrome the vast majority of the tumours involved are in fact endocrine (including oat-cell carcinoma). Oat-cell carcinoma and bronchial carcinoid are the only lung tumours proven to cause Cushing's syndrome. The position is very different with hypercalcaemia; here there is full justification for using the term 'non-endocrine' tumour. Carcinomas of bronchus, kidney, ovary, endometrium, cervix, vulva, pancreas, oesophagus, colon, bladder, renal pelvis, penis, liver and intrahepatic bile ducts, parotid, and adrenal have been incriminated (Snedecor and Baker, 1964; Grimes et al, 1967; Sherwood, O'Riordan, Aurbach, and Potts, 1967). Malignant lymphomas can cause this disorder, which has also been recorded with a leiomyosarcoma 
of the cervix and a hepatic haemangiosarcoma. The number of reasonably well documented cases is now between 50 and 60 .

Renal carcinoma accounts for more than a quarter of reported cases, a striking figure considering that this tumour constitutes only about $2 \%$ of malignant disease. Bronchial carcinoma accounts for about another quarter. If, to the cases quoted by Grimes et al (1967) with data on tumour type, are added those of Snedecor and Baker (1964), Sherwood et al (1967), Strickland, Bold, and Medd (1967) and the present series, a total of 22 bronchial carcinomas results. Of these, 18 are squamous, one is large-cell undifferentiated, two are adenocarcinomas, and one is an oat-cell tumour. The only adenocarcinomas are in our series, but it must be emphasized that in these the hypercalcaemia was mild. In the solitary case of oat-cell carcinoma (Snedecor and Baker, 1964), some vertebral involvement was present, but the low tubular reabsorption of phosphate does suggest that it belongs in the category of tumours under discussion. The striking dominance of squamous tumours is almost certainly significant, but some caution is necessary in interpreting this. In surgical material there is an inherent bias towards squamous tumours because of the greater resectability rate of this tumour type in contrast to, say, oat-cell carcinoma. Similarly, at necropsy, squamous carcinoma is less likely to be associated with widespread metastases than other tumour types. Thus the detection of hypercalcaemia not due to bony metastases is inherently easier with squamous carcinoma for at least two reasons. Nevertheless, it is fair to say that oat-cell carcinoma does not have a greater tendency than other types to induce hypercalcaemia; on the contrary, there is a strong hint of a negative correlation which requires confirmation. The contrast with the lung tumours associated with Cushing's syndrome is noteworthy.

Apart from bronchial and renal carcinoma, the other carcinomas incriminated include squamous, transitional-cell, and adenocarcinomas. Certain facts about these tumours may have a bearing on the pathogenesis. In none of the adenocarcinomas is secretion of mucin mentioned; the tumour types involved are often ones in which production of abundant mucin would not be expected. Only one tumour of the gastrointestinal tract is implicated (Case Records, Massachusetts General Hospital, 1963) and not a single case of gastric carcinoma. Production of a parathormone-like substance by the tumour has been shown in many cases of this syndrome (Tashjian et al, 1964; Sherwood et al, 1967). Hormone synthesis by non-endocrine tumours has been attributed to loss of repressors of DNA in malignant cells (Bennett, 1965). The fact that squamous bronchial tumours rather than adenocarcinomas are mainly implicated and that the tumours are mostly poorly differentiated is relevant to this aberrant hormone production. Tumours like squamous carcinomas, geared to protein synthesis, may be more likely to produce a polypeptide with a parathormone-like action; adenocarcinomas producing abundant mucopolysaccharides are perhaps less liable to do so. Secondly, the tumours in our series are mostly very poorly differentiated and this is also true of the carcinomas of oesophagus and cervix previously mentioned. Dedifferentiation in tumours, associated perhaps with loss of repressors of DNA, may play a part in this secretion of ectopic hormone. Such loss of repression of DNA could lead to polypeptide synthesis with a parathormone-like action.

We wish to thank Professor C. V. Harrison for reading the manuscript and are indebted to the departments of radiotherapy, medicine, and surgery for access to case notes. We are grateful to $\mathrm{Mr}$ B. Chalk and Miss C. Nash for technical and secretarial assistance.

\section{REFERENCES}

Azzopardi, J. G., and Williams, E. D. (1968). Cancer(Philad.), 22, 274. Bennett, I. L., Jr. (1965). Physiol. Phycs, 3 (No. 12), 1.

Carey, V. C. I. (1966). Amer. Rev. resp. Dis., 93, 584.

Gault, M. H., and Kinsella, T. D. (1965). Canad. med. Ass. J., 92, 317. Gilmour, J. R., and Martin, W. J. (1937). J. Path. Bact., 44, 431.

Goldberg, M. F., Tashjian, A. H., Jr., Order, S. E., and Dammin, G. J. (1964). Amer. J. Med., 36, 805.

Gordan, G. S., Cantino, T. J., Erhardt, L., Hansen, J., and Lubich, W. (1966). Science, 151, 1226.

Grimes, B. J., Fisher, B., Finn, F., and Danowski., T. S. (1967). Acta endocr. (Kbh.), 56, 510.

Keller, R. T., Goldschneider, I., and Lafferty, F. W. (1965). J. Amer. med. Ass., 192, 782.

Lamberg, B. A., Pelkonen, R., and Frick, M. H. (1964). Acta med. scand., 176, 187.

Leaf, A. (1961). New Engl. J. Med., 264, 243.

Lipsett, M. B., Odell, W. D., Rosenberg, L. E., and Waldmann, T. A. (1964). Ann. intern. Med., 61, 733.

Locks, M. O. (1962). J. Lancet, 82, 165.

Massachusetts General Hospital Case Records (1963). New Engl. J. Med., 269, 801.

Massaro, D. J., and Owen, J. A. Jr. (1962). Amer. Rev. resp. Dis., $85,727$.

Pentimalli, G. (1960). Ortop. Traum. Appar. mot., 28, 501

Plimpton, C. H., and Gellhorn, A. (1956). Amer.J. Med., 21, 750.

Roth, S. I. (1964). New Engl. J. Med., 270, 902.

Sherwood, L. M., O'Riordan, J. L. H., Aurbach, G. D., and Potts, J. T., Jr. (1967). J. clin. Endocr., 27, 140.

Snedecor, P. A., and Baker, H. W. (1964). Cancer (Philad.), 17, 1492.

Stone, G. E., Waterhouse, C., and Terry, R. (1961). Ann. intern. Med., $54,977$.

Strickland, N. J., Bold, A. M., and Medd, W. E. (1967). Brit. med. J., 3, 590 .

Tashjian, A. H., Jr., Levine, L., and Munson. P. L. (1964). J. exp. Med., 119, 467. 